\title{
Childhood Tuberculosis Treatment Outcome and Its Association with HIV-Co infection in Ethiopia, A Systematic Review and Meta-analysis
}

Getaneh Mulualem Belay ( $\sim$ getanehmulua@gmail.com )

University of Gondar

Chalachew Adugna Wubneh

University of Gondar

Research article

Keywords: Ethiopia, HIV- co infection, Tuberculosis, treatment outcome, childhood

Posted Date: September 8th, 2019

DOI: https://doi.org/10.21203/rs.2.14156/v1

License: @ (i) This work is licensed under a Creative Commons Attribution 4.0 International License. Read Full License

Version of Record: A version of this preprint was published at Tropical Medicine and Health on February 18th, 2020. See the published version at https://doi.org/10.1186/s41182-020-00195-x. 


\section{Abstract}

Introduction Globally around one million children are infected with Tuberculosis. Childhood Tuberculosis is underestimated due diagnosis challenge. HIV infection can affect the TB disease progression and treatment outcome.

Objectives The aim of this systematic review and meta-analysis is to determine the pooled estimates of childhood tuberculosis treatment outcome and to analyze the impact of HIV-co infection.

Methods We searched all available articles using PubMed, Google scholar and a web of science. Additionally, reference lists of included studies and Ethiopian institutional research repositories were used. Searching was limited to studies conducted in Ethiopia and published in English language. Cohort, cross-sectional and case-control studies were included. A weighted inverse variance random effects- model was used. The overall variations between studies were checked by heterogeneity test Higgins's method (I 2 ). All included studies were assessed with the JBI quality appraisal criteria. Publication bias was checked with the funnel plot and Egger's regression test.

Result A total of 6 studies with 5,389 participants were included in this systematic review and meta-analysis. The overall pooled estimate of successful treatment outcome was found to be $79.54 \%$ (95\% Cl: 73.00, 86.07). Of which 72.44\% were treatment completed. Moreover, this study revealed that the treatment failure, defaulter and death were $0.15 \%, 5.36 \%$, and $3.54 \%$, respectively. Poor treatment outcome was higher among children with HIV co infection with an odds ratio of 3.15 (95\% Cl: $1.67,5.94)$ as compared to HIV negative children.

Conclusion The rate of successful treatment outcome of childhood tuberculosis in Ethiopia found to be low compared to the threshold suggested by the world health organization. HIV co infection is significantly associated with poor treatment outcome. Therefore, special attention better to be given for children infected with HIV.

\section{Introduction}

World Health Organization (WHO) reported that globally, 10.0 million people develop TB disease in 2017, from this 1.0 million were children. According to WHO 2018 TB report, in 2017, TB (Tuberculosis) caused an estimated 1.3 million deaths among HIV(Human Immunodeficiency Virus) negative and 300,000 additional deaths from TB and HIV co-infected people(1).

TB is the second leading cause of death from an infectious disease worldwide, after HIV. The WHO declared TB as global public health emergency in 1993 when large number of death occurred due to TB(2). Globally, TB has been reported to be one of the major causes of death among children(3). Approximately 1 million children are estimated to be infected by TB worldwide, of this $75 \%$ occur in the 22 high-burden countries including Ethiopia(4). In high TB burden countries, childhood TB constitutes $20 \%-40 \%$ caseload(5). The true burden of childhood TB is underestimated because of challenge in diagnostic accuracy(6). Childhood TB is a good indication of ongoing transmission of TB in the community(2). Accurate diagnosis and successful treatment of people with TB averts millions of deaths each year (an estimated 54 million over the period 2000-2017), but there are still large and persistent gaps in detection and treatment. The latest treatment outcome data for new cases show a global treatment success rate of $82 \%$ in 2016 . This is a reduction from $86 \%$ in 2013 and $83 \%$ in 2015; in countries where notifications have increased, reporting of treatment outcomes has not kept pace(1).

As Ethiopia is one of the 22 Highest TB burden countries in the world, Federal Ministry of Health of Ethiopia is implementing TB prevention and control program at all level of the health facility. According to Ethiopian national population based tuberculosis prevalence survey conducted in 2011,7.5/100, 000 children were smear positive.(7) In Ethiopia the TB cure rate was $58 \%$ for HIV-positive and $89 \%$ for HIV-negative children(8). Tuberculosis has been recognized as major public health problem in Ethiopia more than half a century ago. Since 1960s tuberculosis controlling effort was started in country(7). The global community has launched TB end strategy. Intensified research and innovation is one of the pillar to achieve the end TB strategy. The research has to focus on discovery, development and rapid uptake of new tools,

Page $2 / 13$ 
interventions and strategies and research to optimize implementation and impact, and promote innovations is one of the pillar among global TB end strategy. Achieving $\geq 90 \%$ TB treatment success rate is one of the top-ten priority indicators for monitoring implementation of the end TB strategy at global and national levels. The other indicator in the TB end strategy is reduction in number of TB deaths. The sustainable development goal has planned to reduce death by $75 \%$ in $2025,90 \%$ by 2030 from 2015 baseline(9).

HIV is considered as fueled factor for TB epidemic. Studies reported that risk of TB in children having HIV is very high. In TB/HIV co-infection often results in disseminated disease, especially in advanced stages of HIV-infection, resulting in poorer survival compared to HIV-negative children (8). Risk of active TB in HIV co-infected children is related to both CD4 count and more indirectly also to viral load. Conversely, restoration of cellular immunity with anti-retroviral therapy partially reverses TB susceptibility(10). In Ethiopia, there is inconsistence of research findings on childhood TB treatment outcome. Therefore, this study will estimate the pooled childhood TB treatment outcome and analyze its association with HIV co-infection.

\section{Methods}

\section{Protocol and registration}

The protocol of this systematic review and meta-analysis was found in the PROSPERO which can be accessed in the web address of https://www.crd.york.ac.uk/PROSPERO/\#myprospero. Moreover, the protocol has been registered in the international prospective systematic review and meta-analysis (PROSPERO) with a registration number of CRD42018110570. For reporting of the findings, the Preferred Reporting Items for Systematic Review and Meta-Analysis (PRISMA) guideline has been utilized (Additional file 1).

\section{Eligibility criteria}

\section{Inclusion criteria}

Study area: All included studies have been conducted in Ethiopia.

Types of studies: In this systematic review and meta-analysis observational studies including case-control, cross sectional and cohort studies that report childhood TB treatment outcome and its associated factors were included. However, we did get case-control studies.

Type of participants: Children less than 15 years those who had tuberculosis and receiving tuberculosis treatment had been enrolled in the review.

Types of intervention: In this review, we compared the TB treatment success rate of HIV Co- infection compared to the counterparts.

Types of outcome measures: In this study, TB treatment success rate defined as both treatment completed and cured cases.

Language: Articles reported in English language were included

\section{Exclusion criteria}

We excluded papers that were not fully accessible, after at least two email contact with the primary author of the paper. Moreover, Editorials, trials, conference papers, qualitative studies, and reviews were excluded.

\section{Information sources}

Both published and unpublished research reports that revealed the childhood TB treatment outcomes and/or its association with HIV co-infection in Ethiopia were included. We searched all available articles using PubMed, Google 
scholar and a web of science. Additionally, reference lists of included studies and institutional research repositories were explored. Searching was limited to studies conducted in Ethiopia and published in English language.

\section{Searching strategy}

We used the following searching terms to search all databases: "tuberculosis treatment", "childhood tuberculosis treatment", "childhood tuberculosis treatment outcome", "tuberculosis", "cured", "completed", "treatment completed", " relapse", " treatment failure", "died", " successful TB treatment outcome", " unsuccessful TB treatment outcome”, "childhood tuberculosis treatment", "outcome of tuberculosis treatment", "factors", "risk factors", " associated factors", "predictors", " HIV co infection”, and "Ethiopia”. The searching string was developed using the Boolean operators 'AND' and 'OR'. PubMed searching was done using this searching strategy (Additional file 2). The last date of PubMed searching was on August, 23, 2019.

\section{Study Selection}

At the beginning, we retrieved all available studies from electronic databases. Those identified studies were imported to the Endnote citation manager and duplicates removed carefully. Second, two independent authors (GMB and CAW) screened and assessed the title and abstracts of studies that imported in the endnote followed by reviewing of the full texts. Discrepancies among reviewers have been solved through discussion and consensus. In addition, disagreements were solved by communicating the authors of the primary studies.

\section{Quality assessment}

Two authors (GMB and CAW) assessed the quality of included studies independently. The Joana Briggs Institute (JBI) critical appraisal tool has been utilized to critically appraise the quality to the studies. JBI critical appraisal checklist for cohort and cross-sectional studies was employed (Additional 3). Discrepancies between the authors have been solved through discussion, repeating the procedure and reaching upon the consensus.

\section{Data collection process and extraction}

After we have developed a data extraction sheet, the first author (GMB) had extracted the following data from the included studies, first of author of the study, study area, region, population, design, sample size, proportion of treatment outcome including cured, treatment completed, treatment failure, died, and relapse, odds ratio of HIV co infection, proportion of treatment success rate, $\log p$, and SE log $p$ and the second author (CAW) checked the extracted data. Any disagreement between authors has been solved by discussion.

\section{Summary measures}

Treatment completed: A patient with TB who completed treatment without evidence of failure, but with no record of sputum smear or culture results, in the last month of treatment.

Cured: A patient with bacteriologically confirmed pulmonary TB at the beginning of treatment who was smear or culturenegative in the last month of treatment

Treatment failure: A TB patient whose sputum smear or culture is positive at 5 month or later during treatment.

Died: A TB patient who died from any cause during treatment.

Successful treatment outcome: If PTB patients were cured (i.e., negative smear microscopy at the end of treatment and on at least one previous follow-up test) or completed treatment with resolution of symptoms. 
Unsuccessful TB treatment outcome: If treatment of PTB/EPTB/ patients resulted in treatment failure (i.e., remaining smearpositive after 5 months of treatment), default (i.e., patients who interrupted their treatment for two consecutive months or more after registration), or death.

\section{Synthesis of results}

Before meta- analysis of the research report, the proportion of treatment outcome and OR of HIV co infection had been transformed to logarism in excel spreadsheet. Then, the excel data exported to STATA version 11 for further analysis. To determine the pooled effect of TB treatment outcome a weighted inverse random effect model was employed. The descriptive data were presented using a table to describe the characteristics of each primary study. Besides, the point prevalence of each study as well as the overall prevalence were described using a forest plot graph. The forest plot was interpreted as follows: the horizontal line shows the $95 \% \mathrm{Cl}$ and the black box represents the Wight of each study. Moreover, an explanatory data analysis using $\mathrm{I}^{2}$ test was conducted to assess the random variations between each primary study. In this study, heterogeneity was interpreted as an $\mathrm{I}^{2}$ value $=0 \%$ no heterogeneity, $25 \%=\mathrm{low}, 50 \%=$ moderate, and $75 \%=$ high (11). Based on the above testes, the primary studies included in this meta-analysis exhibited a significant random variation $\left(I^{2}=\right.$ with Eggers regression test $\mathrm{p}$-value $\left.<0.001\right)$, which forced us to use a random effects meta-analysis model to compute pooled effect. Publication bias was assessed by funnel plot and Egger's test. Statistically significant publication bias was declared at p-value less than 0.05 .

\section{Results}

\section{Study selection and screening}

Totally, we have retrieved 1232 studies of which 1132 were found from PubMed, 34 from a web of science, 51 from Google scholar, 10 from reference lists of the included studies, and the rest 5 were found from Ethiopian institutional research repositories. Primarily, 64 research reports were removed due to duplication, 1096 because of irrelevant title and abstracts. Then after, 72 articles were assessed for the full text review of which 30 articles were removed due to the study area, 11 due to the study designs, 21 due to study population and 4 due to irrelevant report as to the pre specified inclusion criteria. Finally, 6 studies were included in this systematic review and meta-analysis.

\section{Study characteristics}

As described in Table 1, a total of six studies with 5,389 participants were included. All studies published between 20092017 with a follow up period of 5 to 10 years. The follow up period of childhood TB treatment outcome ranged from 1998 to 2013. Regarding the study area, two studies were conducted in Tigray region $(12,13)$, one in Addis Ababa(14), one in Amhara (15), one in Oromia (16), and one in SNNPRS (17). Among the included studies, four $(13,14,16,17)$ were conducted with a retrospective cohort study design, and two $(12,15)$ were retrospective cross-sectional. The minimum and maximum sample size were 226 and 2565, respectively. In this review, the highest TB treatment success rate was reported from Tigray and Addis Ababa (85.5\%) and the lowest from Oromia (66.4\%). Since all eligible studies found were done by using cohort and cross-sectional study design, we assessed the quality of the paper using Joana Briggs Institute (JBI) adapted for cohort and cross-sectional studies. Studies which fitted to $50 \%$ and above the quality assessment checklist were considered low risk and included in this study (Table 1). We found none of studies were excluded after quality assessment.

\section{Meta- analysis}

We performed funnel plot and Egger's regression test to determine the publication bias. Hence, the publication bias was not detected as the funnel plot is symmetrical in observation and the Egger's regression test is 0.203.

\section{Child hood TB Treatment outcome}


All of the included studies had reported the child hood TB treatment outcomes. Consequently, as illustrated in figure 2 , the overall pooled childhood TB treatment success rate was $79.54 \%$ (95\% Cl: $73.00,86.07)$ of which $72.44 \%$ were treatment completed and $7.1 \%$ were cured. Moreover, described in table 2, this study revealed that the treatment failure, defaulter and death were $0.15 \%, 5.36 \%$, and $3.54 \%$, respectively.

\section{The association between TB treatment outcome and HIV co-infection}

To explore the association between TB treatment outcome and TB/HIV co infection, we used 4 studies that reported extractable data that helps to calculate the odds ratio of HIV co infection. As illustrated in (Fig4), the overall pooled odds ratio of unsuccessful TB treatment outcome among HIV co infection was $3.15\left(95 \% \mathrm{Cl}: 1.67,5.94, \mathrm{I}^{2}=65.3 \%, \mathrm{P}\right.$. value $=$ 0.034).

\section{Discussion}

Tuberculosis one of the global burden that highly affect the vulnerable population like children. Successful treatment outcome of childhood tuberculosis is one of the mechanism to reduce its transmission, drug resistance, mortality and morbidity. This systemic review and meta-analysis has shown treatment outcome of childhood tuberculosis and the impact of HIV on successful treatment outcome in Ethiopia context. Even though there are limited study regarding this topic in Ethiopia, we try to analysis six studies to have pooled treatment outcome. In this systemic review successful treatment outcome of childhood TB was $79.54 \%$ (95\% Cl: 73.00, 86.07) which is low from global recommendation suggested by World health organization which $\geq 90 \%$ successful treatment outcome to end TB strategy(1).

This result also low from a study done from South-East Asia region, Bhutan 93\% success treatment outcome (18). This may be due variation in health service standards in Bhutan, all children diagnosis for TB will admitted inpatient for first 2month of treatment for directly observed therapy(DOT) where as in Ethiopia no admission for direct observed therapy(19, 20).

National surveillance study was conducted in England and Wales reported that $88 \%$ of children completed their treatment which higher successful treatment outcome compared with our finding(21). This may be due to the fact that in developed countries quality of care in all aspect is well improved which may have impact in good treatment outcome.

In Pakistan one study show that overall successful treatment outcome (cured and treatment complete) was recorded as $95.1 \%$ which is higher than from our study(22).

The result of this systemic review and meta-analysis was congruent with two studies conducted in Nigeria which was $77.4 \%$ and $83 \%$ of successful treatment outcome of childhood $\operatorname{TB}(23,24)$. And it is also in line with a study conducted from international epidemiological data base network with $80 \%$ of effective treatment outcome among children taking anti TB treatment(25).

This finding was higher with studies conducted Democratic Republic of Congo tertiary hospital which was $70 \%$ successful treatment outcome, of this $69.6 \%$ was treatment completed(26).

\section{HIV/TB-Co-infection on children TB treatment outcome}

In this systemic review and meta-analysis of $20.46 \%$ of children had poor treatment outcome. Among those who had unfavorable treatment outcome treatment failure $0.15 \%$, defaulter $5.36 \%$ and death $3.5 \%$. Poor TB treatment outcome was higher among children with HIV co infection with an odds ratio of 3.15 (95\% Cl: $1.67,5.94)$ as compared to HIV negative children. One study from international epidemiological data base network also reported that HIV/TB children have poor treatment outcome compared with HIV non-infected children(25). One of the major challenges in the managements of children with HIV/TB co-infection is pharmacokinetics interaction of nevirapine based ART regimen and rifampicin-based 
anti-tuberculosis treatment (27). Another study which is conducted in Abidjan, Côte d'Ivoire on impact of HIV infection on outcome of tuberculosis among children revealed that children with HIV infection had higher mortality rate than HIV negative (28). High death rate reported from HIV positive children may associated with immune-compromising that result to other opportunistic infection like pneumonia, meningitis and measles(29). Unlike HIV sero-negative, HIV/TB co-infected children would have worst treatment outcome because they have compromised immunity. As result they may not develop sign and symptom of infection unless it detects advanced diagnostic modality(30). The other reason for poor treatment outcome of HIV/TB con-infected children is severity of illness, as a result of more serious illness are common in HIV infected than HIV negative children taking anti-tuberculosis treatment(31). Therefore, the more the sever the illness will end up with death which the most horrible outcome(10). Among children having unfavorable treatment outcome in this study high proportion were defaulter (5.36\%), this may be associated with pill burden especially in case of children taking TB/HIV treatment at time, intolerable side effect of drug $(32,33)$, social stigma, poor support from social /family and health care inaccessibility $(20,34,35)$. This poor treatment outcome may be due poor adherence to the drug and noncompliance to health care service(35). Especially in Ethiopian there is common practice in case of such serious illness shifting to traditional medicine(36), cultural practice and religious activities this may related with the nature of treatment that takes long time follow up, they may end in fatigue and hopelessness on medical treatment(30, 37).

\section{Limitation}

Data was not retrieved from some regions including, Hareri, Afar, Beshangul Gumze, Dire-Dawa, and Somali, hence, the finding may to representative to these regions.

\section{Conclusion}

Proportion of childhood tuberculosis successful treatment outcome in Ethiopia found to be low compared to the threshold suggested by the world health organization. Presence of HIV co-infection is significantly associated with poor treatment outcome. Therefore, special attention better to be given for children infected with HIV and TB

\section{Abbreviations}

DOT: Directly Observed Therapy

EPTB: Extra Pulmonary Tuberculosis

HIV: Human Immune Deficiency Virus

PTB: Pulmonary Tuberculosis

SNNPRS: Southern Nations, Nationalities and Peoples Region State

TB: Tuberculosis

WHO: World Health Organization

\section{Declarations}

Ethics approval and consent to participate: Not applicable since we used already previously done research

Consent for publication: Not applicable

Availability of data and materials: All data generated or analyzed during study are included in this systematic review and meta-analysis 
Competing interests: The authors declare that they have no conflicts of interest

Funding: No funding

Authors' contributions: Getaneh Mulualem Belay conceived and designed the study. Getaneh Mulualem Belay and Chalachew Adugna Wubneh established the search strategy, extracted the data, assessed the quality of included studies, did the analysis, and finally wrote the review. All authors had prepared the manuscript. Finally, the authors read, modified, and agreed on the final prepared manuscript.

Acknowledgements: Our special gratitude goes to the authors of included studies who helped us to do this systematic review and meta-analysis

\section{References}

1. Organization WH. Global tuberculosis report 2018: World Health Organization; 2018.

2. Organization WH. Global tuberculosis report 2013: World Health Organization; 2013.

3. Dodd PJ, Yuen CM, Sismanidis C, Seddon JA, Jenkins HE. The global burden of tuberculosis mortality in children: a mathematical modelling study. The Lancet Global Health. 2017;5(9):e898-e906.

4. Organization WH. Global tuberculosis control: epidemiology, strategy, financing: WHO report 2009: World Health Organization; 2009.

5. Marais B, Hesseling A, Gie R, Schaaf H, Beyers N. The burden of childhood tuberculosis and the accuracy of community-based surveillance data. The International Journal of Tuberculosis and Lung Disease. 2006;10(3):259-63.

6. Nelson L, Wells C. Global epidemiology of childhood tuberculosis [Childhood TB]. The International journal of Tuberculosis and lung Disease. 2004;8(5):636-47.

7. Kebede A, Alebachew Z, Tsegaye F, Lemma E, Abebe A, Agonafir M, et al. The first population-based national tuberculosis prevalence survey in Ethiopia, 2010-2011. The International Journal of Tuberculosis and Lung Disease. 2014;18(6):635-9.

8. Palme IB, Gudetta B, Bruchfeld J, Muhe L, Giesecke J. Impact of human immunodeficiency virus 1 infection on clinical presentation, treatment outcome and survival in a cohort of Ethiopian children with tuberculosis. The Pediatric infectious disease journal. 2002;21(11):1053-61.

9. Lönnroth K, Raviglione M. The WHO's new End TB Strategy in the post-2015 era of the Sustainable Development Goals. Transactions of the Royal Society of Tropical Medicine and Hygiene. 2016;110(3):148-50.

10. Newton SM, Brent AJ, Anderson S, Whittaker E, Kampmann B. Paediatric tuberculosis. The Lancet infectious diseases. 2008;8(8):498-510.

11. Higgins JP, Thompson SG, Deeks JJ, Altman DG. Measuring inconsistency in meta-analyses. BMJ: British Medical Journal. 2003;327(7414):557.

12. Daemo M, Kelbore A. Treatment outcomes and associated factors of childhood tuberculosis: treated under dots program in health centers of Mekelle Town, Tigray Regional State, Ethiopia. Cent Afr J Public Health. 2016;2(1):11-7.

13. Tilahun G, Gebre-Selassie S. Treatment outcomes of childhood tuberculosis in Addis Ababa: a five-year retrospective analysis. BMC public health. 2016;16(1):612.

14. Hailu D, Abegaz WE, Belay M. Childhood tuberculosis and its treatment outcomes in Addis Ababa: a 5-years retrospective study. BMC pediatrics. 2014;14(1):61.

15. Kebede ZT, Taye BW, Matebe YH. Childhood tuberculosis: management and treatment outcomes among children in Northwest Ethiopia: a cross-sectional study. The Pan African medical journal. 2017;27.

16. Ramos JM, Reyes F, Tesfamariam A. Childhood and adult tuberculosis in a rural hospital in Southeast Ethiopia: a tenyear retrospective study. BMC public health. 2010;10(1):215. 
17. Muňoz-Sellart M, Yassin MA, Tumato M, Merid Y, Cuevas LE. Treatment outcome in children with tuberculosis in southern Ethiopia. Scandinavian journal of infectious diseases. 2009;41(6-7):450-5.

18. Dendup T, Dorji T, Edginton M, Kumar A, Wangchuk D, Dophu U, et al. Childhood tuberculosis in Bhutan: profile and treatment outcomes. Public health action. 2013;3(1):11-4.

19. Sagbakken M, Frich JC, Bjune G. Barriers and enablers in the management of tuberculosis treatment in Addis Ababa, Ethiopia: a qualitative study. BMC public health. 2008;8(1):11.

20. Tadesse T, Demissie M, Berhane Y, Kebede Y, Abebe M. Long distance travelling and financial burdens discourage tuberculosis DOTs treatment initiation and compliance in Ethiopia: a qualitative study. BMC public health. 2013;13(1):424.

21. Abubakar I, Laundy MT, French CE, Shingadia D. Epidemiology and treatment outcome of childhood tuberculosis in England and Wales: 1999-2006. Archives of disease in childhood. 2008;93(12):1017-21.

22. Laghari M, Sulaiman SAS, Khan AH, Memon N. A prospective study of socio-demographic, clinical characteristics and treatment outcomes of children with tuberculosis in Sindh, Pakistan. BMC infectious diseases. 2019;19(1):82.

23. Ogbudebe CL, Adepoju V, Ekerete-Udofia C, Abu E, Egesemba G, Chukwueme N, et al. Childhood Tuberculosis in Nigeria: Disease Presentation and Treatment Outcomes. Health services insights. 2018;11:1178632918757490.

24. Adejumo OA, Daniel OJ, Adebayo BI, Adejumo EN, Jaiyesimi EO, Akang G, et al. Treatment outcomes of childhood TB in Lagos, Nigeria. Journal of tropical pediatrics. 2015;62(2):131-8.

25. Carlucci JG, Blevins MP, Kipp AM, Lindegren ML, Du QT, Renner L, et al. Tuberculosis Treatment Outcomes Among HIV/TB-Coinfected Children in the International Epidemiology Databases to Evaluate AIDS (leDEA) Network. Journal of acquired immune deficiency syndromes (1999). 2017;75(2):156-63.

26. Aketi L, Kashongwe Z, Kinsiona C, Fueza SB, Kokolomami J, Bolie G, et al. Childhood tuberculosis in a sub-Saharan tertiary facility: epidemiology and factors associated with treatment outcome. PloS one. 2016;11(4):e0153914.

27. Oudijk JM, McIlleron H, Mulenga V, Chintu C, Merry C, Walker AS, et al. Pharmacokinetics of nevirapine in HIV-infected children under 3 years on rifampicin-based antituberculosis treatment. Aids. 2012;26(12):1523-8.

28. Mukadi YD, Wiktor SZ, Coulibaly I-M, Coulibaly D, Mbengue A, Folquet AM, et al. Impact of HIV infection on the development, clinical presentation, and outcome of tuberculosis among children in Abidjan, Cote d'Ivoire. Aids. 1997;11(9):1151-8.

29. Lucas SB, Peacock CS, Hounnou A, Brattegaard K, Koffi K, Honde M, et al. Disease in children infected with HIV in Abidjan, Cote d'Ivoire. Bmj. 1996;312(7027):335-8.

30. Kebede A, Wabe NT. Medication adherence and its determinants among patients on concomitant tuberculosis and antiretroviral therapy in South West Ethiopia. North American journal of medical sciences. 2012;4(2):67.

31. Venturini E, Turkova A, Chiappini E, Galli L, de Martino M, Thorne C. Tuberculosis and HIV co-infection in children. BMC infectious diseases. 2014;14(1):S5.

32. Walters E, Cotton MF, Rabie H, Schaaf HS, Walters LO, Marais BJ. Clinical presentation and outcome of tuberculosis in human immunodeficiency virus infected children on anti-retroviral therapy. BMC pediatrics. 2008;8(1):1.

33. Nachega JB, Parienti J-J, Uthman OA, Gross R, Dowdy DW, Sax PE, et al. Lower pill burden and once-daily antiretroviral treatment regimens for HIV infection: a meta-analysis of randomized controlled trials. Clinical infectious diseases. 2014;58(9):1297-307.

34. De Vries AM, Kimpen JL, Donald PR, Schaaf SH, Soeters M. Clinical features and outcome in children admitted to a TB hospital in the Western Cape-the influence of HIV infection and drug resistance. South African Medical Journal.

2005;95(8):602-6.

35. Castelnuovo B. Review of compliance to anti tuberculosis treatment and risk factors for defaulting treatment in Sub Saharan Africa. African health sciences. 2010;10(4). 
36. Alevtina G, Zerihun S. Ethiopian Traditional and Herbal Medications and their Interactions with Conventional Drugs.

Ethiopian Journal of Health Development. 2009;20:127-34.

37. Gebremariam MK, Bjune GA, Frich JC. Barriers and facilitators of adherence to TB treatment in patients on concomitant TB and HIV treatment: a qualitative study. BMC public health. 2010;10(1):651.

\section{Tables}

Table 1: General characteristics of included studies

\begin{tabular}{|c|c|c|c|c|c|c|c|c|}
\hline $\begin{array}{l}\text { Author/year } \\
\text { of } \\
\text { publication }\end{array}$ & $\begin{array}{l}\text { Study } \\
\text { area }\end{array}$ & Region & Study design & $\begin{array}{l}\text { Study } \\
\text { population }\end{array}$ & $\begin{array}{l}\text { follow } \\
\text { up } \\
\text { period }\end{array}$ & $\begin{array}{l}\text { Sample } \\
\text { size }\end{array}$ & $\begin{array}{l}\text { treatment } \\
\text { success } \\
\text { rate }\end{array}$ & $\begin{array}{l}\text { Quality } \\
\text { assessment } \\
\text { result }\end{array}$ \\
\hline $\begin{array}{l}\text { Tilahun } \\
\text { G/2016 (13) }\end{array}$ & Mekelle & Tigray & $\begin{array}{l}\text { Retrospective } \\
\text { cohort }\end{array}$ & $\begin{array}{l}\text { children < } \\
15 \text { years } \\
\text { of age }\end{array}$ & $\begin{array}{l}2009- \\
2013\end{array}$ & 491 & 85.5 & Low risk \\
\hline $\begin{array}{l}\text { Ramos } \\
\text { GM/2010 } \\
(16)\end{array}$ & $\begin{array}{l}\text { Arsi } \\
\text { zone }\end{array}$ & Oromia & $\begin{array}{l}\text { Retrospective } \\
\text { cohort }\end{array}$ & $\begin{array}{l}\text { children < } \\
15 \text { years } \\
\text { of age }\end{array}$ & $\begin{array}{l}1998- \\
2007\end{array}$ & 1029 & 66.4 & Low risk \\
\hline $\begin{array}{l}\text { Munez } \\
\text { sellart } \\
\text { M/2009(17) }\end{array}$ & $\begin{array}{l}\text { Sidama } \\
\text { zone }\end{array}$ & SNNPRS & $\begin{array}{l}\text { Retrospective } \\
\text { cohort }\end{array}$ & $\begin{array}{l}\text { children < } \\
15 \text { years } \\
\text { of age }\end{array}$ & $\begin{array}{l}2002- \\
2007\end{array}$ & 851 & 77 & Low risk \\
\hline $\begin{array}{l}\text { Kebede } \\
\text { ZT/2017(15) }\end{array}$ & Gondar & Amhara & $\begin{array}{l}\text { Cross- } \\
\text { sectional }\end{array}$ & $\begin{array}{l}\text { children }< \\
15 \text { years } \\
\text { of age }\end{array}$ & NA & 227 & 78.9 & Low risk \\
\hline $\begin{array}{l}\text { Hailu D } \\
\text { /2014 (14) }\end{array}$ & $\begin{array}{l}\text { Addis } \\
\text { Ababa }\end{array}$ & $\begin{array}{l}\text { Addis } \\
\text { Ababa }\end{array}$ & $\begin{array}{l}\text { Retrospective } \\
\text { cohort }\end{array}$ & $\begin{array}{l}\text { children < } \\
15 \text { years } \\
\text { of age }\end{array}$ & $\begin{array}{l}2007- \\
2011\end{array}$ & 2565 & 85.5 & Low risk \\
\hline $\begin{array}{l}\text { Daemo Md } \\
\text { /2016(12) }\end{array}$ & Mekelle & Tigray & $\begin{array}{l}\text { Retrospective } \\
\text { Cross- } \\
\text { sectional }\end{array}$ & $\begin{array}{l}\text { children < } \\
15 \text { years } \\
\text { of age }\end{array}$ & $\begin{array}{l}\text { 2007- } \\
2011\end{array}$ & 226 & 84 & Low risk \\
\hline
\end{tabular}

Table 2: Childhood Tuberculosis treatment outcome

\begin{tabular}{|l|l|l|l|l|l|}
\hline Region & \multicolumn{3}{|l|}{ Successful TB treatment outcome } & \multicolumn{3}{l|}{ Unsuccessful TB treatment outcome } \\
\hline & $\begin{array}{l}\text { Treatment } \\
\text { completed (\%) }\end{array}$ & Cured (\%) & Failure (\%) & Died (\%) & $\begin{array}{l}\text { Defaulter } \\
\text { (\%) }\end{array}$ \\
\hline Amhara & $74.9 \%$ & $4 \%$ & $0.0 \%$ & $3.3 \%$ & $3.8 \%$ \\
\hline Oromia & $56.8 \%$ & $9.6 \%$ & $0.2 \%$ & $3.9 \%$ & $13.9 \%$ \\
\hline Addis Ababa & $78.9 \%$ & $6.6 \%$ & $0.23 \%$ & $3.24 \%$ & $3.9 \%$ \\
\hline Tigray & $79.4 \%$ & $5.35 \%$ & $0.225 \%$ & $2.65 \%$ & $4.55 \%$ \\
\hline SPPRS & $65.6 \%$ & $11.4 \%$ & $0.3 \%$ & $5.8 \%$ & $1.8 \%$ \\
\hline $\begin{array}{l}\text { Pooled with } \\
\text { 95\% CI }\end{array}$ & $72.44(95 \%$ CI: & $7.14(95 \%$ CI: & $0.15(95 \%$ CI:0.01,0.28) & $3.54(95 \%$ CI: & $5.36(95 \%$ \\
CI:2.62,8.10) \\
\hline
\end{tabular}

\section{Additional Files}

Additional file 1: The PRISMA guideline

Additional file 2: The searching terms for PubMed

Additional file 3: The JBI quality assessment tool for cohort and cross sectional studies

Figures 


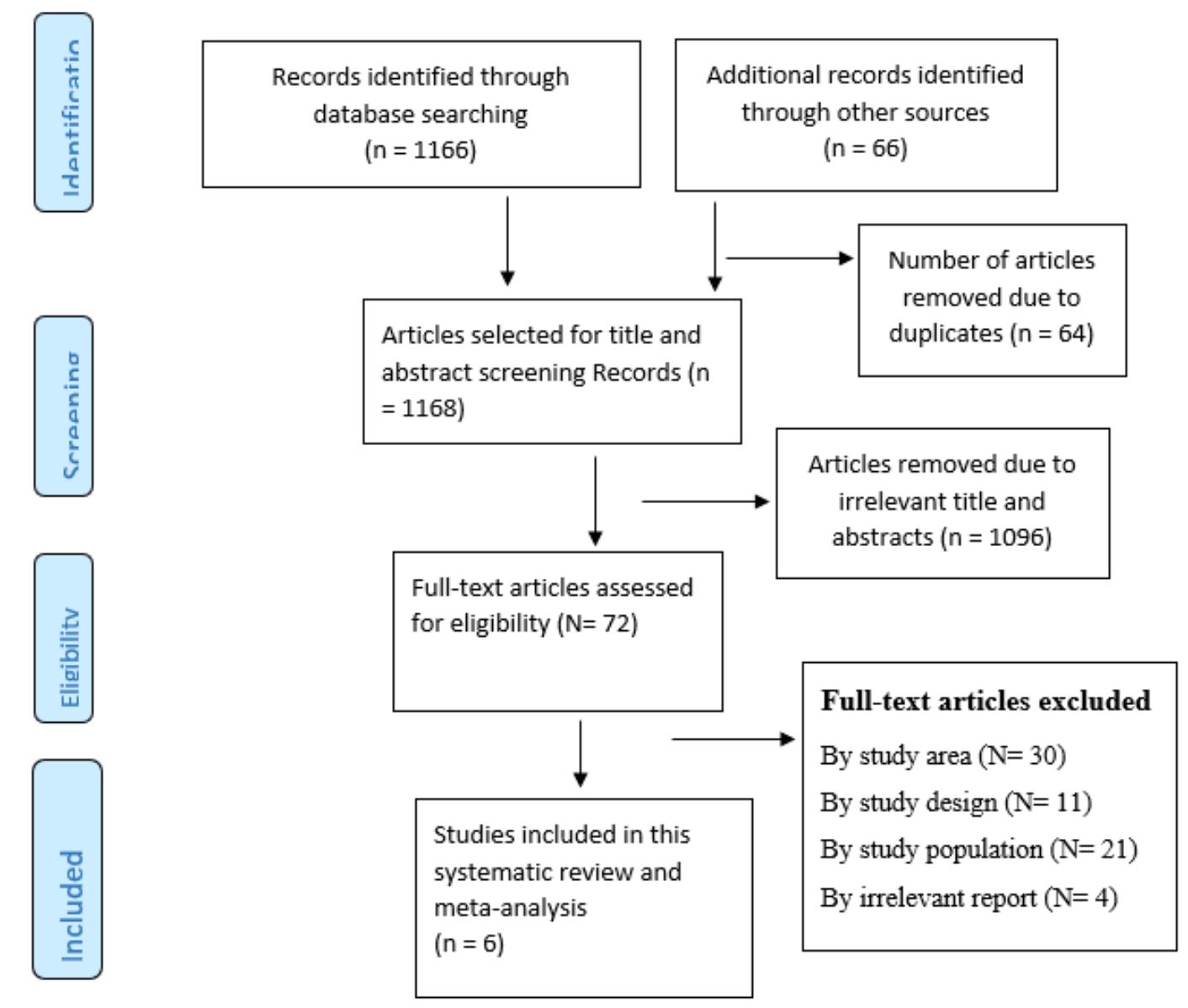

\section{Figure 1}

Flow diagram of articles selection and screening 


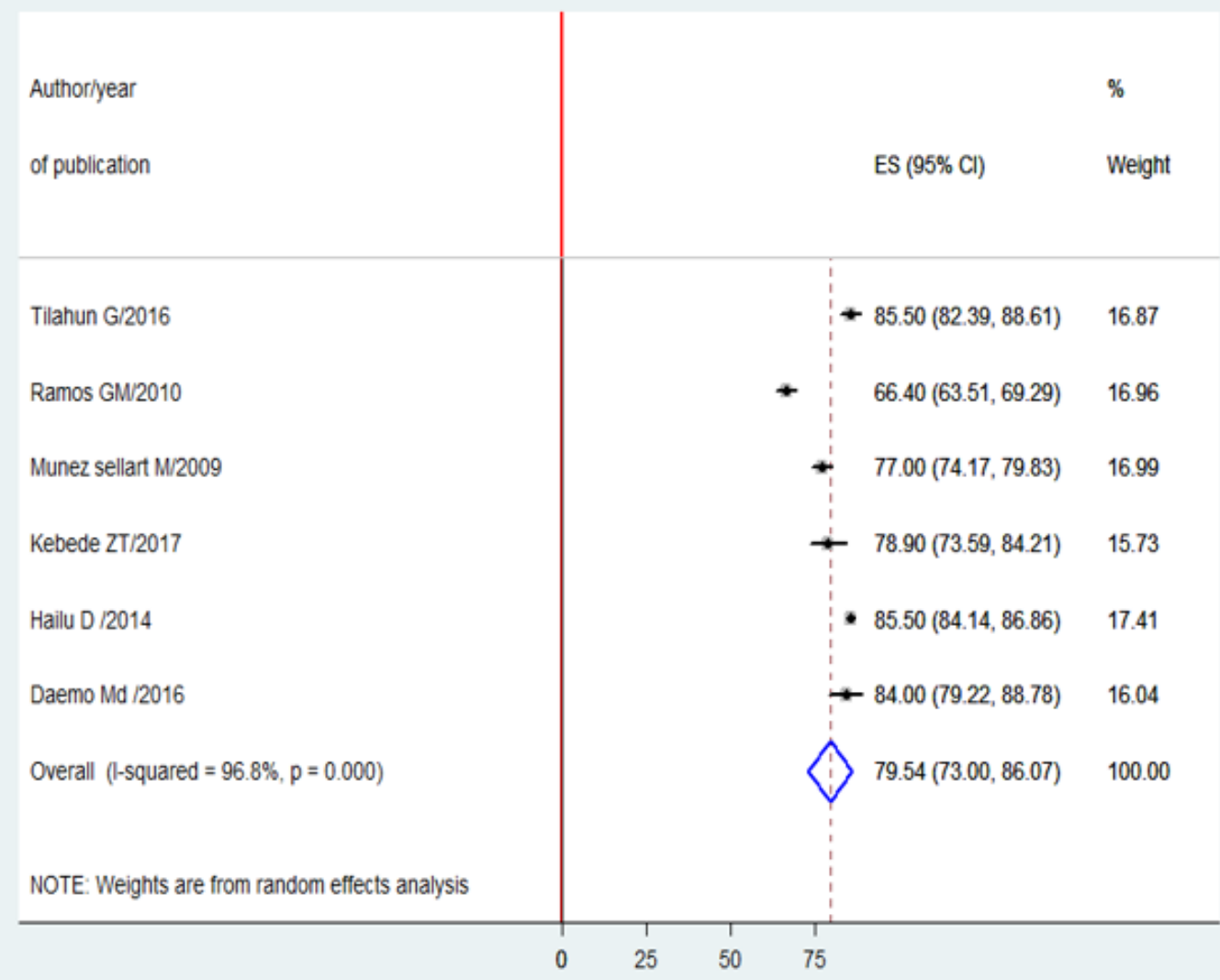

Figure 2

Forest plot of successful TB treatment outcome with 95\% $\mathrm{Cl}$.

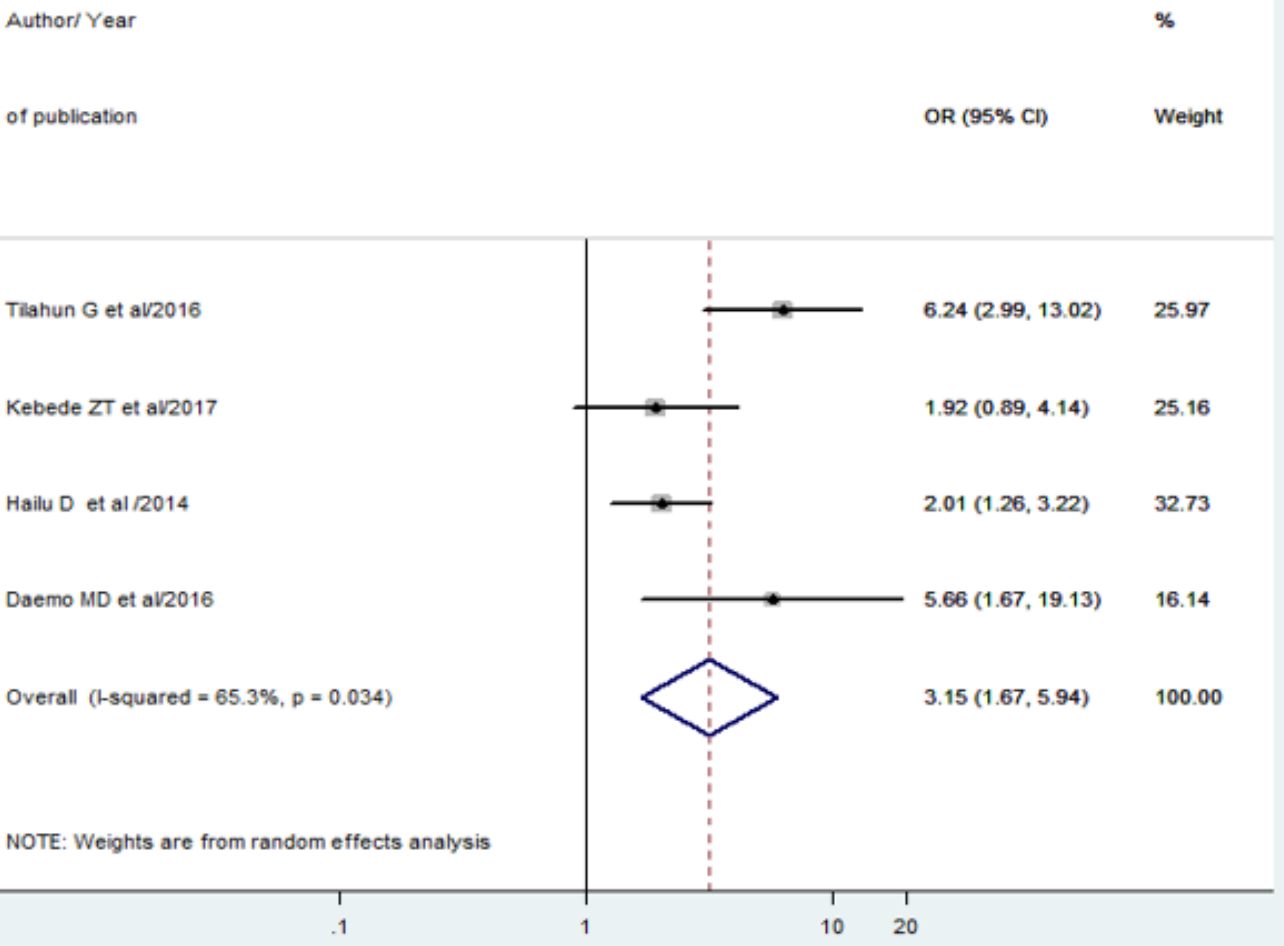




\section{Figure 3}

Forest plot of the odds ratio of TB treatment outcome among TB/HIV co infection.

\section{Supplementary Files}

This is a list of supplementary files associated with this preprint. Click to download.

- Additionalfile1.docx

- Additionalfile2.docx

- Additionalfile3.docx 